\title{
Utopia eleitoral: a experiência do PCB e de Carlos Marighella nas eleições de 1945 na Bahia*1
}

\section{Electoral utopia: The experience of PCB and Carlos Marighella in the 1945 elections in Bahia}

Ricardo José Sizilio²

* Recebido em: 14/08/2014. Aprovado em: 01/11/2014.

1 Uma versão reduzida deste artigo foi publicada com o título "De prisões à Constituinte - A vitória de Carlos Marighella e do PCB nas eleições de 1945" nos Anais da IX Semana de História Política / Seminário Nacional de História: Política Cultura \& Sociedade. UERJ. 2014.

2 Mestrando em História Social pela Universidade Federal da Bahia. Bolsista FAPESB. Contato: ricardosizilio@yahoo.com.br

\section{Resumo}

Em 1945, após quinze anos no poder, Getúlio Vargas iniciou o processo de redemocratização do Brasil, tentando conter as pressões de diversos segmentos da sociedade que desejavam o fim do seu governo. Além de convocar as eleições para o final do ano, anistiou os presos políticos encarcerados durante a ditadura do Estado Novo. Com a abertura política, Carlos Marighella pode concorrer, pela Bahia, ao pleito em dezembro de 1945, elegendo-se deputado pelo Partido Comunista do Brasil (PCB). Pretendemos discutir neste artigo os caminhos percorridos pelo PCB durante o processo eleitoral de 1945 na Bahia. Através, principalmente, do jornal A Tarde e do periódico comunista O Momento buscamos compreender quais as bandeiras levantas e disputas travadas pelo PCB nessas eleições. Nos interessa neste trabalho, também, entender como Carlos Marighella conseguiu, depois de dez anos longe do seu estado natal, se tornar o único Deputado Federal comunista eleito pela Bahia. Palavras-chave: Partido Comunista do Brasil. Carlos Marighella. Eleições. Bahia.

\begin{abstract}
1945, after fifteen years in power, the brazilian re-democratization process had been started by Vargas, he tried to contain the pressures from many society segments which used to wish the end of Vargas' Government. Besides calling elections for the end of that year he granted amnesty to political prisoners from the dictatorship of the Estado Novo. With this political opening, Carlos Marighella could be candidate by Bahia state in December 1945, and he was elected deputy from the Partido Comunista do Brasil (PCB). This article aims at analyzing the path of PCB throughout the election process of 1945 in Bahia. Our primary sources, A Tarde and the comunist newspaper O Momento, guide our studies to better understand PCB choices and disputes during the elections. It is also our goal to clarify how Carlos Marighella became the only comunist congressman elected by Bahia, despite being away from his home state for ten years.
\end{abstract}

Keywords: Communist Party of Brazil. Carlos Marighella. Elections. Bahia. 


\section{Introdução}

Se as coisas são inatingíveis... ora! Não é motivo para não querê-las... Que tristes os caminhos se não fora

A mágica presença das estrelas! Mário Quintana. Das Utopias

A poesia de Mário Quintana se encaixa com o momento histórico vivido pelos brasileiros que queriam o fim da ditadura de Getúlio Vargas e o retorno das eleições, principalmente entre os anos de 1943 e 1945. No entanto, não pensamos a utopia do fim da ditadura de Vargas e do ressurgimento do processo eleitoral na perspectiva de Quintana que trata utopia como algo inatingível. Utopia para nós é tratada como algo difícil, mas possível de ser alcançado, que requer luta e conhecimento da realidade para sua transformação.

Instalado na Presidência da República desde 1930 e governando ditatorialmente a partir da implantação do Estado Novo em 1937, Getúlio Vargas manteve-se no poder até 1945 utilizando, entre outros instrumentos, a repressão maciça a seus opositores. A derrocada do regime ditatorial pareceu utopia durante anos, no entanto foi se tornando realidade paulatinamente na primeira metade da década de 1940. Grande parte dos brasileiros clamava pelo fim da ditadura e via na realização das eleições e na elaboração de uma nova Constituição a possibilidade concreta de terem muitos dos seus direitos usurpados por Vargas, garantidos.

A iminência do fim da Segunda Guerra Mundial com a vitória dos Aliados, na qual o Brasil fazia parte, carregando consigo o discurso pela democracia era utilizada pelos opositores para pressionar o fim do regime ditatorial. Vargas buscando contornar a situação desfavorável, tendo em vista o aspecto eleitoral, iniciou nos primeiros meses de 1945 o processo de abertura política. Nessa perspectiva buscaremos, ao longo deste texto, percorrer os focos de tensão ao regime Estado-novista, principalmente na Bahia, além de buscar compreender o processo eleitoral de 1945 e a vitória de Carlos Marighella à Deputado Federal Constituinte pelo PCB naquele ano.

\section{Oposição na Bahia ao Estado Novo: Autono- mistas, comunistas ${ }^{2}$, e trabalhadores ${ }^{3}$}

2 Ressaltamos que utilizamos o termo comunistas para designar os militantes do Partido Comunista do Brasil.

3 Optamos aqui por enfatizar esses agentes de oposição ao Es-
Na Bahia, assim como em outros estados, políticos e trabalhadores pressionavam pelo fim do governo autoritário de Vargas, tendo como fatores contribuintes para tal a conjuntura internacional e o crescente descrédito nos regimes fascista e nazista, além do arrocho em que os trabalhadores viviam principalmente devido aos esforços de guerra. Um foco irradiador de oposição a Vargas foi a Concentração Autonomista da Bahia que, desde o início da década de 1930, agregou antigos adversários na busca da autonomia política do estado diante da nomeação de interventores para a chefia do governo. Esta oposição aumentou durante o Estado Novo quando Juracy Magalhães, antigo interventor e afilhado político, rompeu suas relações com o ditador. Tal rompimento permitiu, em 1945, a união de Juracy com Otávio Mangabeira que, embora exilado, era o principal articulador dos Autonomistas. A partir dessa união, esse grupo reuniu quase todas as lideranças liberais da política baiana num bloco antivarguista, utilizando-se da imprensa, da Ordem dos Advogados do Brasil (OAB) e da Faculdade de Direito como centros irradiadores de seus discursos, artigos, moções e manifestos. (SILVA, 2011, p. 39-42)

A Faculdade de Direito era um dos focos de concentração dos liberais Autonomistas, mas também abrigava o Centro Acadêmico Rui Barbosa, que era um importante espaço para os comunistas, mesmo que o partido não estivesse com suas atividades legalizadas. O Partido Comunista do Brasil (PCB), criado em março de 1922, esteve até 1945 na maioria do tempo na ilegalidade. Funcionou de forma legal apenas três meses após sua criação e entre janeiro e agosto de 1927. Mesmo durante os períodos de ilegalidade os comunistas continuavam atuando, o que ocasionou perseguições e inúmeras prisões em todo Brasil, principalmente durante o período em que Getúlio Vargas esteve no poder. Diante da situação precária de sobrevivência política, não é difícil imaginar que os comunistas fossem os maiores opositores a Vargas, exigindo sua deposição imediata. No entanto, desde a rearticulação do partido na "Conferência da Mantiqueira" em 1943, a linha po-

tado Novo, sem com isso negar a existência de outros focos de luta contra o Regime de Vargas. Cabe ressaltar, também, que buscamos compreender algumas das lutas desses grupos sem fazer com isso uma distinção deliberada entre trabalhadores e os comunistas e autonomistas. 
lítica adotada foi a da União Nacional, que desde 1938 pregava que os comunistas deveriam se aliar a todo e qualquer setor que combatesse o fascismo, no Brasil, os integralistas, mesmo que para tal fosse necessária a união com Vargas. Além de combater o fascismo, os comunistas lutavam, entre outros, pela legalização do partido, pela realização de eleições e pela elaboração de uma nova constituição, defendendo sobretudo a "ordem e a tranquilidade"(SENA JÚNIOR, 2007, p. 253-288).

Diante das perseguições políticas durante o Estado Novo e das inúmeras prisões dos comunistas em todo o Brasil, no final da década de 1930, o Comitê Regional da Bahia (CR-BA) se transformou em um dos poucos organismos do partido em funcionamento. A atuação contínua do CR-BA possibilitou, que no início dos anos 1940, os comunistas baianos já estivessem inseridos no movimento estudantil e entre os operários, além de publicarem uma revista de circulação nacional, a Seiva. ${ }^{4}$ Em Salvador, os comunistas atuavam em pelo menos 20 núcleos, e "entre os estudantes havia 7 células do partido funcionando normalmente e 13 células entre os operários" de diversas categorias. A atuação contínua, mesmo que de forma ilegal, e a iminência do fim da Segunda Guerra Mundial tendo a União das Repúblicas Socialistas Soviéticas (URSS) entre os aliados e lutando pela democracia, contribuiu para que os comunistas baianos angariassem um grande capital político. Segundo João Falcão, "no início de 1945, o partido [...] crescia rapidamente, em função do grande número de operários e trabalhadores em geral, estudantes, jornalistas e profissionais liberais que procuravam filiar-se" (FALCÃO, 2000, p. 93-94).

Os comunistas procuraram se inserir ao máximo entre os trabalhadores e em suas organizações, afinal, desde sua criação, o partido aspirava representá-los. Em abril de 1945, o partido criou o Movimento Unificador dos Trabalhadores (MUT), um organismo intersindical que no seu manifesto de lançamento foi "assinado por mais de trezentos líderes sindicais de 13 estados", disputando com as antigas lideranças o controle dos sindicatos e estreitando a relação com os tra-

4 A Revista Seiva foi criada por alguns comunistas baianos e foi o primeiro periódico antifascista a circular no cenário do Estado Novo entre os anos de 1938 e 1943. A respeito da Revista Seiva ver: (FERREIRA, 2012) balhadores (SILVA; SANTANA, 2007, p. 106). Para Petilda Serva Vazquez na organização dos trabalhadores o PCB melhor atuou, mesmo com o processo eleitoral em curso. Para a autora, o PCB "dirigiu seus maiores esforços, não em direção a planos eleitorais, mas a um programa que beneficiava a criação de organismos agregadores da classe trabalhadora" (VAZQUEZ, 1986, p. 81). O ambiente para lutas no seio da classe trabalhadora era fecundo, pois, depois da declaração de guerra aos países do Eixo em 1942, o Brasil iniciou uma sucessiva supressão, mesmo que temporariamente, de direitos trabalhistas adquiridos, gerando grande insatisfação entre os trabalhadores.

A insatisfação dos trabalhadores com a situação de arrocho vivida foi demonstrada por meio das greves a partir de 1944. Desde a chegada de Getúlio Vargas ao poder e ao longo de 13 anos até a Consolidação das Leis Trabalhistas (CLT), foi criada gradativamente legislação que avançava nas conquistas dos trabalhadores. Contudo, a Constituição de 1937 impedia a realização das greves, instrumento legítimo da luta dos empregados contra os patrões. O artigo 139 da Carta Constitucional afirmava que a "greve e o lock-out são declarados recursos antissociais nocivos ao trabalho e ao capital e incompatíveis com os superiores interesses da produção nacional". Com a regulamentação do funcionamento da Justiça do Trabalho em 1939, os grevistas estavam passíveis de punições como suspensão do trabalho, demissão ou até mesmo a prisão, sendo tais punições ratificadas pela CLT em 1943. Sobre a possibilidade de prisão dos trabalhadores, o Código Penal de 1940 estabelecia entre seus artigos que a participação em greve poderia ser sancionada com prisão de um mês a dois anos. ${ }^{5}$

A partir de 1942, no contexto da Segunda Guerra Mundial (1939-1945), "com a lei de esforço de guerra, teve início para os trabalhadores um processo sucessivo de suspensão de direitos trabalhistas" como, por exemplo, o aumento da jornada de trabalho de

Parte da legislação que citamos neste estudo e que tange aos direitos trabalhistas e suas restrições se encontra disponível em: <http://www.planalto.gov.br/ccivil_03/decreto-lei/ del2848.htm>.; <http://www.planalto.gov.br/ccivil_03/decreto-lei/1937-1946/Del1237.htm>.; <http://www.planalto. gov.br/ccivil_03/constituicao/constituicao37.htm>.; <http:// www.planalto.gov.br/ccivil_03/decreto-lei/del5452.htm>. Acesso em: 27 abr. 2014. 
oito para dez horas e a permissão do trabalho noturno para mulheres e crianças (COSTA, 1999, p. 94). Nessa conjuntura de suspensão dos direitos trabalhistas conquistados ao longo de anos, surgiram, em 1944, as primeiras greves desde a implantação do Estado Novo. Os trabalhadores, mesmo com o risco de prisão, enfrentaram o sistema de vigilância dos órgãos de repressão e do Ministério da Guerra, na busca por melhores condições de vida e trabalho. "Em Salvador, a primeira manifestação grevista a aparecer na imprensa foi a greve da "Junta Comercial" entre março e abril, e em 1945 foram contabilizadas pelo menos seis greves na Bahia. Deve-se levar em consideração que esses dados são imprecisos, afinal a imprensa estava sob censura do Departamento de Imprensa e Propaganda, fazendo com que muitas das greves não tivessem sido noticiadas (SENA JÚNIOR, 2007, p. 276-277 e 443).

Com o aumento do arrocho e da insatisfação entre os trabalhadores, o PCB buscou estreitar os laços com estes, inclusive com a criação da MUT como dito anteriormente. No entanto, devido à linha adotada de "ordem e tranquilidade", o PCB tentava conter as greves, pois o partido entendia que, diante da situação do país, era necessário o máximo de esforço dos trabalhadores para evitar qualquer tipo de instabilidade, sendo necessária, inclusive, a união com a burguesia. O PCB entendia naquele momento que o Brasil deveria superar seus resquícios feudais, e a união da classe trabalhadora com o empresariado era fundamental para o desenvolvimento do país, partindo da ideia de que para a implantação do comunismo no país era preciso que o Brasil passasse antes pela etapa "democrático-burguesa" (SILVA; SANTANA, 2007, p. 106-107).

\section{Legislação e partidos: a caminho das elei- ções}

Havia, no início de 1945, convergência de interesses entre liberais, comunistas e trabalhadores na busca por mudanças políticas e no retorno à democracia. O que parecia ser utopia alguns anos antes passou a ser vislumbrado, apresentando-se cada vez mais como possibilidade real. A conjuntura política favorecia a articulação das forças opositoras para a derrubada da ditadura, no entanto, Getúlio Vargas percebendo a situação desfavorável à continuidade do regime ditatorial, tendo em perspectiva os interesses eleitorais futuros, deu o passo inicial para a abertura política do Brasil. O Ato Adicional número 9, promulgado em 28 de fevereiro de 1945, determinava, entre outras providências, que, no prazo de 90 dias, seria baixado novo decreto fixando a data das eleições gerais para presidente, senadores e deputados. O regime do Estado Novo, ao que parecia, vivia seus últimos momentos, e Vargas tentava com isso comandar o processo de redemocratização no Brasil (SILVA, 1976, p. 112). A partir do Ato Adicional 9, a Justiça Eleitoral deveria ser totalmente reorganizada em 90 dias, haja vista que, criada em 1932 pelo próprio Getúlio, perdeu suas funções com o Estado Novo, afinal os partidos foram extintos e proibidos de funcionar pelo Decreto-Lei 37 de 1937 e o Congresso foi dissolvido pelo art. 178 da Constituição de 1937 (SOUZA, 2010, p. 48).

O processo de reabertura política foi realizado de forma bastante lenta e até meados de abril havia no Brasil aproximadamente 600 presos políticos encarcerados. Por isso, comunistas, liberais, integralistas e outros segmentos da sociedade brasileira pressionavam o governo pela anistia, como se pode verificar com a realização da "Semana Nacional da Anistia na Bahia"6 no início daquele mês. Com o intuito de conter a pressão da opinião pública e de seus opositores, Vargas anistiou os presos políticos e exilados, em sua maioria integralistas e comunistas, e entre os que foram soltos estavam Carlos Marighella e Luis Carlos Prestes.

Continuando o processo de abertura política, foi assinado por Vargas, em 28 de maio, o Decreto-Lei 7586 que regulamentava todo o processo eleitoral. As diversas agremiações partidárias, que já estavam em pleno funcionamento desde abril, foram registradas junto ao Tribunal Superior Eleitoral (TSE) entre junho e novembro, sendo necessária para tal, a assinatura de pelo menos 10.000 eleitores distribuídos em pelo menos 5 estados. Os principais partidos que concorreram ao pleito de 02 de dezembro de 1945 foram: o Partido Social Democrático (PSD), a União Democrática Nacional (UDN), o Partido Trabalhista Brasileiro (PTB), o PCB e o Partido de Representação Popular (PRP). ${ }^{7}$

$6 \quad$ A Tarde. A Semana Nacional de Anistia na Bahia. 09 de abril de 1945, p. 2. Biblioteca Pública do Estado da Bahia (BPEB). Setor: Periódicos Raros, Acervo: Jornais.

7 Segundo Gilberto Callil, até 1964 o PRP, de orientação fas- 
O registro do PCB junto ao TSE não transcorreu facilmente. Em agosto o partido reformulou seu estatuto e, como exigia a legislação, no mês posterior, deu entrada no requerimento de registro provisório. Contudo, foi solicitado pelo relator do processo explicações sobre o programa do partido. Os comunistas tiveram que discorrer sobre como pretendiam realizar a divisão de terras no país, combater os fascistas, socializar os meios de produção e, ao final, como estratégia, os comunistas negaram os princípios marxistas-leninistas. Durante os meses que durou o processo de registro do $\mathrm{PCB}$, foi requerida pela União Social pelos Direitos do Homem sediada em São Paulo, a proibição da concessão do registro partidário. Dentre os argumentos utilizados, um chama atenção, pois afirmava que os comunistas eram violentamente anti-democráticos e fundamentalmente nazistas. Com o mesmo intuito, telegramas foram enviados ao TSE como, por exemplo, o da professora Maria Joaquina Ferreira, da Bahia, informando ser mãe de família, que educava quatro filhos com os preceitos cristãos e que, por isso, pedia a negativa do registro ao $\mathrm{PCB} .{ }^{8} \mathrm{O}$ registro definitivo do partido só foi concedido em 10 de novembro, depois de todos os trâmites e exigências do Tribunal, mas tanto o fato de o relator pedir explicações, como as solicitações de negativa ao registro indicam que os comunistas eram vistos com bastante desconfiança e que a campanha anticomunistas ao longo de anos, tinha alcançado seus objetivos.

Para o pleito que estava em curso, a legislação também teve novidades a respeito do financiamento eleitoral e sobre os candidatos. Na campanha eleitoral em 1945, foi proibido o financiamento de campanha por meio de recursos de origem estrangeira, seja por indivíduos, empresas ou quaisquer outras fontes, no entanto, não mencionava proibição a doações de indivíduos ou de empresas nacionais (SOUZA, 2010, p. 21). Tal proibição continua vigente até os dias atuais

cista, teve grande importância na política brasileira. Nas eleição de 1945 o PRP não conseguiu eleger algum deputado ou senador. Na Bahia, o partido foi combatido maciçamente pelos jornais $O$ Momento e A Tarde e ainda assim obteve grande votação. Faltou ao PRP nas eleições de 1945 na Bahia, aproximadamente 1.500 votos para eleger um deputado.

8 Os documentos citados foram solicitados pelo autor ao Tribunal Superior Eleitoral por e-mail e disponibilizados da mesma forma. A documentação se encontra na Seção de Arquivos da referida instituição. e, sugere que tal limitação tenha se dado por receio de possíveis interferências na política nacional por parte de outros países ou organismos internacionais, principalmente após a Segunda Guerra Mundial em que se exaltava o discurso nacionalista. Ademais, nos parece razoável que houvesse, por parte daqueles que elaboraram a legislação eleitoral, o temor de que a URSS, uma das vencedoras no conflito mundial, pudesse contribuir maciçamente com recursos financeiros para o Partido Comunista do Brasil, fazendo com que seus candidatos tivessem grande êxito nas eleições a serem realizadas. Já em relação aos candidatos, a legislação tinha algumas peculiaridades, como a possibilidade de um candidato concorrer concomitantemente ao Senado e à Câmara dos Deputados e, ainda, por diversos estados. Outra novidade do Decreto-Lei era o fato de que somente os partidos poderiam indicar os candidatos ao pleito de dezembro.

Ainda segundo a legislação, eram considerados eleitores os brasileiros maiores de 18 anos independentemente do sexo, com exceção dos analfabetos, dos praças das Forças Armadas, dos mendigos e dos que estivessem, temporária ou definitivamente, privados dos direitos políticos. Era opcional o alistamento dos inválidos; dos maiores de 65 anos; dos brasileiros a serviço do País no estrangeiro; dos oficiais das Forças Armadas em serviço ativo; dos funcionários públicos em gozo de licença ou férias fora de seu domicílio e os magistrados. Cabe ressaltar que o Código Eleitoral garantia à maioria das mulheres o direito ao voto e não o dever, pois só era obrigatório o voto para as mulheres que comprovassem o exercício de algum tipo de profissão lucrativa. Na prática, em 1945 o voto feminino só era obrigatório a uma parcela extremamente reduzida das mulheres.

$\mathrm{O}$ alistamento do eleitorado durou pouco menos de três meses e os trâmites para a concessão dos registros aos partidos políticos aproximadamente seis. Se a luta pelo retorno à democracia durou anos, todo o processo para a realização das eleições foi demasiadamente curto, o que impediu que ela tivesse uma abrangência maior do ponto de vista da participação popular, exemplificado pela exclusão de grande parte dos indivíduos que poderiam ter direito ao voto. Se a eleição em 02 de dezembro foi limitada em muitos aspectos, entendemos que ela o foi de forma proposital, com intuito de manter os mesmos agentes políticos de 
momentos anteriores no parlamento e no executivo. Da mesma forma, com o processo eleitoral passava-se a ideia de participação popular, mas ao garantir a aproximadamente $10 \%$ da população o direito ao voto, o que existia na verdade era um grande processo de exclusão, tais quais os demais processos eleitorais anteriores.

\section{O cenário eleitoral baiano e a plataforma política do PCB}

Estabelecida a legislação eleitoral e o funcionamento dos partidos, o PCB na Bahia, mostrou, por meio de comícios e do seu jornal O Momento quais seriam os seus candidatos para o pleito de dezembro de 1945. Durante a campanha eleitoral, os comunistas levantaram diversas bandeiras divulgadas principalmente pelo jornal O Momento, dentre as quais estavam o combate aos integralistas; a conclamação por uma Constituinte e a revogação da Constituição de 1937; a defesa pelo voto dos militares de baixa patente das Forças Armadas e dos analfabetos. Além destas divulgadas em seu periódico no programa de partido enviado ao TSE para seu registro político, o PCB se propôs a lutar, entre outros, pela emancipação da mulher e pelo reconhecimento de todos os seus direitos que lhe eram negados; pela proteção à infância, à velhice e aos inválidos; e pelo esmagamento político e moral dos remanescentes do fascismo. Como a disputa política já estava sendo travada desde o início do ano, as bandeiras políticas do PCB eram divulgadas em O Momento antes mesmo da regulamentação do processo eleitoral. Às vésperas de findar o prazo de 90 dias para a regulamentação e tendo conhecimento do anteprojeto de lei, foi publicada, em 14 de maio, a reportagem Pelo voto dos soldados. ${ }^{9}$ Nela foi feita uma ampla defesa pelo direito ao voto dos soldados das Forças Armadas, ${ }^{10} \mathrm{ci}$ -

9 O Momento. Pelo voto dos soldados. 14 de maio de 1945, p. 2. Biblioteca Pública do Estado da Bahia.(BPEB). Setor: Periódicos Raros, Acervo: Jornais.

10 Na reportagem em O Momento se entende como Soldado, todos os Praças das Forças Armadas que não teriam direito ao voto pelo anteprojeto do Decreto-lei que regulamentaria as eleições de 1945. Para melhor esclarecimento, nas Forças Armadas há a divisão entre Praças e Oficiais. São Praças os militares de patentes mais baixas e que não podem chegar as funções de comando e são subordinados aos Oficiais. São denominados Praças: Os Soldados, Cabos e Sargentos. tando o patriotismo destes na luta pela democracia em solo europeu e que os oficiais poderiam votar, logo, o voto não era uma incompatibilidade com a profissão militar, mas sim uma questão de classe e, por fim, conclamava os responsáveis pela redação final do texto do anteprojeto para que em tempo pudessem fazer as alterações necessárias a fim de que os soldados tivessem direito ao voto, o que não foi atendido.

Durante toda a campanha eleitoral, o jornal $O$ Momento foi fundamental para o PCB no estado, haja vista que por meio dele se propagava as ideias da direção do partido aos seus militantes. Em 06 de agosto, na matéria $O$ Partido Comunista e o problema eleitoral, foi afirmado que "O Partido Comunista não descansará [...] na tarefa de fazer com que o povo participe cada vez mais da nossa vida política e nesse sentido lutará até o fim pelo direito de voto para os analfabetos".11 Para compreender que a defesa dos comunistas em relação ao voto dos analfabetos era plausível, confrontamos os números do Censo Demográfico de 1940 da Bahia ${ }^{12}$ com a quantidade de eleitores inscritos no TRE-BA em 1945. Cabe salientar ainda que números do Censo não tratam com exatidão a quantidade populacional, além de estarem defasados em relação à eleição, afinal, há diferença de cinco anos para o pleito de 02 de dezembro de 1945. Os dados do censo informam que a Bahia possuía um total de 3.918.112 habitantes, sendo 1.827 .887 a partir dos 20 anos obrigados pela legislação a votar. Porém, destes, apenas 29\% (524.925 pessoas) declaravam saber ler e escrever. ${ }^{13}$ Assim, ficariam excluídas de votar 1.302.962 pessoas por serem analfabetas, o que equivale aproximadamente a $71 \%$ das que teriam a obrigação de serem eleitoras. Essa projeção seria para o ano de 1940, ainda assim, para

11 O Momento. O Partido Comunista e o problema eleitoral. 06 de agosto de 1945, p. 6. Biblioteca Pública do Estado da Bahia (BPEB), Setor: Periódicos Raros, Acervo: Jornais.

12 IBGE. Biblioteca do IBGE. Recenseamento Geral do Brasil. Censo Demográfico. Vol II. 1940. Disponível em: <http:// biblioteca.ibge.gov.br/visualizacao/periodicos/65/cd_1940 v2_br.pdf>.

13 Cabe ressaltar aqui que, para efeito eleitoral, desde a Constituição de 1934 eram obrigados a se alistar todos os homens a partir dos 18 anos e as mulheres que comprovassem renda. Contudo, o Censo de 1940 não utiliza esse critério de divisão de faixa etária. Para uma análise mais próxima do objetivo da pesquisa, utilizamos aqui os dados da população acima dos 20 anos, incluindo aquela acima de 65 anos que eram facultadas de votar. 
a eleição em dezembro de 1945 o TRE-BA inscreveu em todo território baiano entre 08 de julho e 02 de outubro, 440.823 eleitores, aproximadamente $11 \%$ da população de 1940 .

Segundo o Instituto Brasileiro de Geografia e Estatística (IBGE, 1940), a taxa de analfabetismo no Brasil na década de 1940 das pessoas a partir dos 10 anos era de 56\%. Na Bahia o problema da falta de instrução era bem pior, haja vista que a taxa de analfabetismo era de aproximadamente $80 \%$ das pessoas a partir dos 15 anos e de $71 \%$ das pessoas a partir dos 20 anos. Diante desses números e com o processo eleitoral em curso, foi realizada pelo PCB na Bahia, por meio dos Comitês Populares Democráticos, uma campanha de alfabetização nos adultos com o objetivo de levar o maior número de eleitores às urnas. Esses Comitês Populares foram criados na década de 1940 e "se constituíram em órgãos cuja tarefa principal era organizar o povo, no sentido de desenvolver o trabalho de massas" fazendo com que os comunistas se aproximassem da população nos bairros e soubessem quais eram de fato suas reivindicações. Buscava-se, desta forma, a organização da sociedade civil nos moldes democráticos, além da ampliação das bases do PCB em Salvador. ${ }^{14}$

Além dos analfabetos serem impedidos de votar, outros critérios da legislação eleitoral podem ter propiciado a diminuição da quantidade de eleitores inscritos. Em 1945, as mulheres só eram obrigadas a votar caso comprovassem atividade lucrativa, o que fazia com que o voto feminino fosse basicamente opcional. A respeito dessa obrigatoriedade, os dados do Censo de 1940 se mostram muito menos precisos, ${ }^{15}$ pois, além de não demonstrarem com exatidão se a atividade exercida pelas mulheres era remunerada, não há como confrontar se as pessoas que trabalhavam

14 A respeito dos Comitês Populares Democráticos ver: (SILVA, 2012, p. 37-76)

15 Os dados do censo não são precisos quanto a atividade ser lucrativa, apenas informa o ramo de atividade exercida. Não há como precisar se todos que trabalhavam na pecuária ou agricultura eram remunerados, ainda assim utilizamos aqui para demarcar como atividade lucrativa as seguintes atividades (agricultura, pecuária e silvicultura; industrias extrativa e de mineração; comércio de mercadorias e de imóveis; transporte e comunicação; administração, justiça e ensino público; defesa nacional e segurança pública; profissões liberais, culto, ensino particular, administração privada; serviços e atividades sociais) também sabiam ler e escrever. Contudo, analisando-se apenas o ramo de atividade, sem levar em consideração a instrução, há como projetar a quantidade de mulheres, caso a eleição fosse em 1940, que deveriam votar. Das 1.827.887 pessoas acima dos 20 anos, aproximadamente 52\% (955.311) eram mulheres e, desse total, apenas 17\% (168.272) exerciam atividade lucrativa. Sabendo que o voto feminino era na prática opcional, havia, portanto, a necessidade dos partidos de estimular a participação das mulheres para o pleito.

Coerente com seu programa e na busca por ampliar sua base eleitoral, o PCB incentivou a participação feminina na campanha eleitoral, exemplificada pela reportagem de $\mathrm{O}$ Momento em 15 de outubro, $\mathrm{A} \mathrm{Mu}$ lher bahiana na luta pacífica pela democracia na qual noticiava a instalação da União Democrática Feminina na Bahia, entidade que se propunha "lutar pela participação da mulher bahiana na vida política e cultural do país”. Na mesma edição, é feita a convocação para o comício no Pelourinho no dia 17, que entre os oradores falaria em "nome da mulher comunista, a militante Lourdes Dias". ${ }^{16}$ No entanto, se a participação feminina na campanha era evidenciada no jornal comunista, isto não significa dizer que houve ampla participação das mulheres entre os candidatos que disputavam o pleito. O Mapa Eleitoral de 1945 do TRE-BA mostra que dos 143 candidatos a deputado, havia apenas três mulheres, a saber: Leolina Costa do PTB que teve 456 votos, Jacinta Amado do PCB que teve 44 votos e Ana Dantas do PRP que teve 18 votos. Nenhuma foi eleita, assim como nenhuma mulher no Brasil ocupou uma das cadeiras da Constituinte de 1946.

Apenas três partidos tinham candidatas, entre eles, o integralista PRP. Em inúmeras edições de $\mathrm{O}$ Momento durante o ano 1945, evidenciava-se a preocupação em combater o nazifascismo, em território nacional, e particularmente na Bahia, em consonância com o programa do PCB. A campanha anti-integralista em O Momento se justificava tanto pelas questões ideológicas, quanto pelo conhecimento da força política que os integralistas tiveram durante a década de 1930 na Bahia, onde possuíam inúmeros jornais tanto na capital como no interior, criando uma rede de informação

16 O Momento. A Mulher bahiana na luta pacífica pela democracia. 15 de outubro de 1945. Biblioteca Pública do Estado da Bahia (BPEB), Setor: Periódicos Raros, Acervo: Jornais. 
e doutrinação dos Camisas Verdes baianos. O Imparcial, A Província, O Popular, O Operário e A Voz do Estudante com sede em Salvador, e no interior $A$ voz do Sigma e O Jornal em Jequié, O Sigma em Itabuna, A Faula de Maragogipe, O Serrinhense de Serrinha, $O$ Sertão de Lençóis, A Mocidade de Santo Amaro da Purificação eram os jornais que formavam a rede integralista na Bahia (CAVALARI, 1999).

Na busca contínua de diminuir a força dos integralistas, o jornal $O$ Momento de 28 de maio publicou uma carta de Carlos Marighella informando o porquê da necessidade de se combater o integralismo. Além dessa carta, a reportagem $O$ povo baiano repele o integralismo - reagirá organizadamente contra as manobras dos fascistas brasileiros, divulgava que os estudantes baianos reunidos na sede da União dos Estudantes da Bahia (UEB) decidiram fazer manifesto contrário a qualquer tentativa de reorganização do partido integralista, além da preparação de uma semana anti-integralista na Bahia. ${ }^{17}$ Em outra matéria, no dia 17 de setembro, o jornal comunista publicou: Permitir a rearticulação integralista é um ultraje a democracia, e na continuação da reportagem, afirmava: No Estado integralista a propensão é no sentido da ditadura... Consiste na concepção totalitária do Universo, dos homens, da elite e das massas. Eis por que considero uma necessidade crucial a de abrir os olhos a opinião brasileira contra os falsos pregadores de doutrinas perigosas. ${ }^{18}$

O jornal $O$ Momento não era o único que publicava matérias contrárias à rearticulação integralista. Ao longo de 1945 o periódico liberal A Tarde publicou inúmeras matérias repudiando a rearticulação integralista por meio do PRP, tais como: O Integralismo no Tribunal da opinião pública ${ }^{19}$ e $A$ mulher baiana contra $o$ integralismo. ${ }^{20} \mathrm{~A}$ campanha anti-integralista realiza-

17 O Momento. O povo baiano repele o integralismo - reagirá organizadamente contra as manobras dos fascistas brasileiros. 28 de maio de 1945. Biblioteca Pública do Estado da Bahia (BPEB), Setor: Periódicos Raros, Acervo: Jornais.

18 O Momento. Permitir a rearticulação integralista é um ultraje a democracia. 28 de maio de 1945. Biblioteca Pública do Estado da Bahia (BPEB), Setor: Periódicos Raros, Acervo: Jornais.

19 A Tarde. O Integralismo no Tribunal da opinião pública. 29 de maio de 1945. Biblioteca Pública do Estado da Bahia (BPEB). Setor: Periódicos Raros, Acervo: Jornais.

20 A Tarde. A Mulher baiana contra o integralismo. 17 de julho de 1945. Biblioteca Pública do Estado da Bahia (BPEB). Se- da por baianos e brasileiros muito se deu pelo impacto da derrota do nazifascismo na Segunda Guerra Mundial e pela ânsia por dias democráticos, criando diversas dificuldades ao movimento integralista. Uma das mais evidentes dificuldades dos integralistas foi tornar insustentável a veiculação de um discurso abertamente contrário à democracia liberal, aos partidos políticos e ao sistema representativo, embora o PRP tenha se mantido na política brasileira até 1964 (CALIL, 2010).

Por outro lado, no que tange à disputa eleitoral em si, o combate dos comunistas aos integralistas tinha um motivo a mais, afinal o PRP se declarava como "a possibilidade de que todos os trabalhadores brasileiros tem de defender seus interesses, que também são os interesses da nacionalidade, os interesses do nosso Brasil". ${ }^{21}$ Percebemos nesse trecho que o PRP buscava também disputar os votos dos trabalhadores, além de contra-atacar o PCB insinuando que os comunistas não defendiam os interesses do Brasil.

\section{0 resultado eleitoral e a vitória do PCB e de Carlos Marighella}

Todo o processo eleitoral se deu em pouco mais de seis meses e durante esse tempo houve acirrada campanha eleitoral em âmbito nacional, tanto para a presidência da república, quanto para os cargos de senadores e deputados que seriam os responsáveis pela elaboração da nova Constituição Brasileira. Para as eleições de 02 de dezembro de 1945 o TRE-BA inscreveu em todo o território baiano 440.823 eleitores, como dito anteriormente. Salvador, a capital do estado e cidade de maior disputa eleitoral, tinha aproximadamente 18\% (78.816) do eleitorado, seguida por Ilhéus e Itabuna com 4\% e 3\% (16.730 e 14.128) dos eleitores, respectivamente. Segundo os dados do Censo Demográfico e Econômico da Bahia de 1940, Ilhéus e Itabuna eram as cidades mais populosas do interior baiano devido, principalmente, à cacauicultura que atraía um grande contingente populacional. Estas cidades junto com Salvador tinham aproximadamente 25\% de todo eleitorado da Bahia que contava com 150 municípios.

tor: Periódicos Raros, Acervo: Jornais.

${ }^{21}$ A Tarde. O Partido de Representação Popular. 19 de novembro de 1945. Biblioteca Pública do Estado da Bahia (BPEB). Setor: Periódicos Raros, Acervo: Jornais. 
É plausível pensar que os partidos tenham concentrado suas campanhas prioritariamente nessas cidades.

Nessa campanha, Carlos Marighella, um dos candidatos a deputado pelo PCB utilizou o jornal O Momento como um dos principais instrumentos para propagar suas ideias, combater o integralismo e também para se fazer conhecido entre os comunistas baianos.

Nascido em Salvador em 1911, Marighella ainda estudante do segundo ano do curso de engenharia civil, foi, preso pela primeira vez, em 1932, ao participar de uma manifestação liderada por estudantes do curso de medicina contra o governo Vargas. Os estudantes baianos apoiaram os descontentamentos dos paulistas que foram às armas contra o presidente, que após iniciar seu governo, revogou a Constituição e nomeou interventores para os estados. Marighella ficou preso junto a outros 511 estudantes e professores por dois dias e esta foi, durante ao longo de sua vida, a sua mais curta temporada na cadeia e única no seu estado natal.

Quando Marighella foi preso em Salvador, ele ainda não era militante do PCB. Sua entrada no partido acontecera pouco tempo antes de ele sair de Salvador com destino ao Rio de Janeiro para militar no centro político do país. A respeito de sua entrada no $\mathrm{PCB}$, ele assim o descreveu:

Em 1934 eu tinha 22 anos de idade [...] participava da Federação Vermelha dos Estudantes e liderei uma série de movimentos na Escola [Politécnica] razão pela qual fui afastado. [...] Logo fui recrutado para o partido e ingressei em uma célula de trabalhadores de tecido. Nesse período organizei as células do partido entre os trabalhadores do porto da Bahia, entre os trabalhadores do serviço de bondes da cidade, entre padeiros etc. e cheguei a ser o secretário do partido, havendo também organizado a Juventude Comunista. ${ }^{22}$

Segundo o próprio Marighella, o motivo pelo qual decidiu se tornar comunista foi "um sentimento profundo ante a injustiça social [que] não me permitia prosseguir em busca de um diploma dedicar-me a engenharia civil, num país onde as crianças são obrigadas a trabalhar para comer" (MARIGHELLA, 1995, p. 23).

Devido a sua atuação política e ao autoritarismo do governo de Vargas, ficou preso entre 1936 e 1937

22 Autobiografia de Carlos Marighella em 7 páginas, 26 de maio de 1954, manuscrito em espanhol. Fundo 495, armazenamento 197, dossiê 170. Arquivo Estatal de História Política e Social da Rússia -RGASPI. em seguida entre 1939 e 1945 na Ilha de Fernando de Noronha e na Ilha Grande. Após ter sido anistiado em 18 de abril de 1945 pode exercer seus direitos políticos e concorrer às eleições, retornando a Bahia entre o final de maio e início de junho, aos 33 anos. Marighella retornou a Bahia depois de quase dez anos longe, entre o Rio de Janeiro e São Paulo realizando atividades ligadas ao partido, e tendo ficado a maior parte desse período em prisões. (NOVA; NÓVOA, 1999)

Tanto Marighella como os demais comunistas, que haviam vivido no passado curtos períodos de legalidade, puderam, entre os anos de 1945 a 1947, "pela primeira vez em sua história se apresentar [...] perante a sociedade brasileira e disputar as preferências do eleitorado e da opinião pública" (VINHAS, 1982, p. 87).

Segundo Falcão, foi submetido pelo Comitê Regional ao Comitê Nacional uma primeira lista contendo onze nomes para serem candidatos pela Bahia, incluindo nessa lista o nome de Carlos Marighella (FALCÃO, 2000, p. 299). Para Basbaum, a escolha dos candidatos do PCB ao pleito de 1945 foi feita exclusivamente pelo Comitê Nacional, mesmo que Prestes tivesse feito "uma promessa formal [...] de que os candidatos a deputados, a senador e a Presidente da República resultasse de uma consulta aos Comitês Populares [no entanto, a escolha foi] feita à revelia desses comitês e das próprias bases do partido" (BASBAUM, 1976, p. 194). Por meio de ambos depoimentos percebemos que havia centralização por parte do Comitê Nacional em relação a escolha dos candidatos ao pleito de 1945, sendo intermediada, no entanto, pelos Comitês Regionais, sem que houvesse a participação dos Comitês Populares, células do partido ou outras instâncias da base nessas escolhas.

Após retornar a Salvador, Marighella passou a circular pela cidade levando a mensagem do partido, haja vista que ele era membro do Comitê Nacional, embora ainda não oficializado como candidato. Segundo Luis Contreiras ${ }^{23}$, Marighella frequentava principalmente a região portuária da cidade, um dos locais onde começara sua militância política. Em junho Marighella discursou no MUT-BA, buscando, inclusive, estreitar

23 Luis Contreiras de Almeida é engenheiro e entrou no PCB em 1945 quando ainda era estudante da Escola Politécnica da Bahia, militando na Bahia durante a campanha eleitoral em 1945. 
sua ligação com os trabalhadores e com o movimento sindical. Mas foi com a oficialização da sua candidatura em outubro que se intensificou a campanha eleitoral na Bahia, predominantemente em Salvador. Sobre essa campanha, Luís Contreiras nos diz:

Foi uma campanha forte. Marighella fez diversos comícios. O "problema" dele é que era muito fluente. Ele tinha dificuldade em terminar um discurso. Os comícios de Marighella não tiveram essa "audiência" que teve o de Prestes [...] era pra 100, 200 pessoas. Ele falava nos bairros, falava nas docas, falava para os portuários. Falou na Liberdade, no comício de Prestes. Foi uma campanha intensa. Às vezes tinha comício dia sim, dia não. Realizava dois, três comícios na semana. ${ }^{24}$

A realização de muitos comícios e sabatinas era fundamental, haja vista que Marighella não era em 1945 um agente político que desfrutava de expressivo reconhecimento público na Bahia e tão pouco era o principal nome do PCB no estado. Além de Marighella, o PCB teve outros 23 candidatos a deputado ${ }^{25}$, incluindo Luís Carlos Prestes que concorreu tanto para deputado como para senador, já que a legislação assim permitia. Entre o retorno de Marighella à Bahia e as eleições transcorreram-se aproximadamente seis meses. Durante esse período Carlos Marighella não se dedicou apenas à disputa eleitoral na Bahia, ele por fazer parte do Comitê Nacional teve que cumprir com diversas outras obrigações do partido em outros estados, como em Minas Gerais e no Distrito Federal. Ainda assim, ao final da apuração, Marighella se consagrou como candidato mais votado do partido com 5.187 votos, sendo o único comunista eleito pela Bahia à Constituinte.

Das 24 cadeiras que a Bahia tinha direito na Câmara dos Deputados 12 foram ocupadas por membros

24 Entrevista realizada pelo autor em 10 de setembro de 2013.

25 Há divergências quanto ao número de candidatos a deputado pelo $\mathrm{PCB}$ que concorreram às eleições. Segundo $O$ Momento o PCB teve 24 candidatos, enquanto o $A$ Tarde divulgou uma lista constando 25 nomes. Após confrontarmos as duas listas percebemos que o A Tarde divulgou o nome do candidato Joaquim Seixas Vale Cabral repetidamente usando dois nomes diferentes: Joaquim Seixas e Vale Cabral. Ao divulgar o resultado eleitoral a lista do TRE-BA constava 23 candidatos do PCB excluindo o nome de Aydano Couto Ferraz. Entendemos, embora existam essas divergências, que o PCB teve 24 candidatos a deputados, pois é provável que Aydano Couto Ferraz não tenha sido votado e por isso não conste na lista do TRE. da UDN. Entre os eleitos por este partido, estavam os "Autonomistas" Otavio Mangabeira e Juracy Magalhães, antigos adversários de Vargas (SILVA, 1992, p. 22). As demais cadeiras da Câmara foram ocupadas, principalmente pelo PSD, com nove deputados eleitos e as três últimas foram ocupadas pelos deputados do PTB, PCB e PPS. Diferente do ocorrido na Bahia, o PSD conseguiu a maioria na Constituinte, ao eleger 159 deputados (53\% do total da Câmara), seguido pela UDN com 78 deputados (26\%), PTB com 22 deputados (7\%) e PCB com 15 deputados (5\%). Outros cinco partidos elegeram os 23 deputados que faltavam para completar os 297 que compuseram a Câmara dos Deputados. Nota-se, que na Bahia, o resultado das eleições para deputado ratificou o PSD e a UDN como as principais forças eleitorais do país, no entanto houve uma inversão no resultado no estado em relação ao resultado geral no Brasil, haja vista que a UDN conseguiu eleger mais deputados do que o PSD.

Se o resultado eleitoral para deputado na Bahia não reproduziu o que aconteceu de uma forma geral no Brasil, na eleição para presidente o cenário eleitoral baiano refletiu o que aconteceu no país. Com a apuração dos resultados, o candidato a presidente Eurico Gaspar Dutra do PSD, que foi eleito presidente da república, também foi o mais votado na Bahia com aproximadamente 53\% dos votos (186.747), seguido por Eduardo Gomes da UDN com 41\% (144.564). O $3^{\circ}$ colocado foi Yedo Fiuza, candidato do PCB que obteve $6 \%$ dos votos (22.059), e por fim, Mario Teles do desconhecido PAN (Partido Agrário Nacional) recebeu insignificantes 63 votos. ${ }^{26}$ Foram computados, ao final das eleições, 350.893 votos para presidente e $2.570 \mathrm{em}$ branco, totalizando 353.433 de votos válidos, ou seja, $80 \%$ da quantidade de eleitores inscritos para o pleito. O relatório da comissão apuradora sobre as eleições, registrado em Ata e publicado no Boletim Eleitoral em 30 de março de 1946, informa que 63 sessões em todo o estado tiveram seus votos anulados, devido principalmente ao encerramento das atividades eleitorais antes do horário previsto. Embora os dados do TRE-BA não informem a quantidade de votos nulos na eleição para presidente e mesmo levando em consideração que os

26 Dados contidos na Ata da Seção do Tribunal Regional Eleitoral do Estado da Bahia, publicada no Boletim Eleitoral de 30 de março de 1946. 
votos de 63 sessões tenham sido anulados, há a defasagem de $20 \%$ em relação aos eleitores inscritos, o que sugere, como possibilidades, o descrédito dos candidatos, a dificuldade de deslocamento dos eleitores para realizar a votação ou mesmo a indiferença de parte do eleitorado frente ao processo eleitoral. Nas eleições presidenciais posteriores, em 1950 e 1955 o percentual de abstenções no estado foi de aproximadamente 30\% e $55 \%$ respectivamente o que indica a probabilidade de um crescente desinteresse no processo eleitoral por parte dos baianos.

\section{Considerações finais}

Baseada na legislação eleitoral de 1945, a Lei dos Partidos Políticos (Lei no 9.096, de 1995) ${ }^{27}$ é restritiva até os dias atuais sobre o financiamento por parte de entidades ou governos estrangeiros, contudo não há um controle efetivo do financiamento internacional nas campanhas políticas, pois a legislação em vigor não restringe as doações feitas por empresas nacionais que possuam capital internacional investido, o que torna a legislação de alguma forma ineficaz.

Confrontando os dados dos Censos de 1940 na Bahia com a quantidade de eleitores inscritos cinco anos depois, confirma-se a ideia de exclusão de grande parte da população do processo eleitoral no Brasil. O direito ao voto era limitado a uma parcela minoritária da população, prática realizada desde a primeira Constituição, em 1824, no entanto, com a República mudaram-se os parâmetros de exclusão.

Permeada por questões ideológicas, a disputa eleitoral na Bahia entre comunistas e integralistas foi acirrada, justificando as inúmeras matérias em $\mathrm{O} M o$ mento durante o ano de 1945. A repulsa aos integralistas era ideológica, sem dúvida, mas nos parece viável a possibilidade do temor dos comunistas em relação à capacidade eleitoral do PRP. Tal preocupação, não pode ser desprezada, pois, analisando-se os dados da eleição para deputado, enquanto o PCB obteve 18.628 votos, elegendo Marighella à Câmara dos Deputados, o PRP, mesmo com toda propaganda contra, conseguiu 12.913 votos, faltando aproximadamente 1.500

27 É possível visualizar a Lei dos Partidos em: <http://www.planalto.gov.br/ccivil_03/leis/19096.htm>. Acesso em: 15 set. 2013. votos para eleger um deputado pela Bahia, haja vista que o quociente eleitoral era de 14.437 votos. ${ }^{28}$ Outro fator que demonstra a força dos integralistas refere-se ao número de votos obtidos pelo candidato Carlos de Farias Albuquerque, que não se elegeu: 6.136 votos, quase 1.000 votos a mais que Carlos Marighella, deputado eleito pelo PCB e mais de 2.000 votos em relação a Theodolo Lins de Albuquerque, eleito pelo Partido Popular Sindicalista.

A direção do PCB em 1945 entendia que o Brasil antes de chegar ao comunismo necessitava passar pela etapa "democrático-burguesa", na qual as eleições fazem parte do processo. Com o processo eleitoral, é plausível pensar que o PCB não fizesse o cálculo estritamente eleitoral e que a defesa do voto dos soldados e dos analfabetos, além da inserção das mulheres na disputa eleitoral, fizessem parte da ideologia defendida pelos comunistas e ratificada em seu programa. No entanto, podemos considerar que o PCB objetivava eleger o maior número de militantes para a Constituinte, por isso, o partido em sua estratégia política, ao lutar pela ampliação do voto, o fazia também por visualizar naqueles grupos possíveis eleitores.

Diante do exposto, diferentemente do que defende Petilda Serva Vazquez (1986) e corroborada por Paulo Santos Silva (1992), entendemos que o PCB não preferiu a criação de organismos sindicais no ano de $1945 \mathrm{em}$ detrimento ao processo eleitoral em curso. Percebemos que o PCB antes mesmo da sua regularização junto ao TSE já estava nas ruas fazendo campanha e durante os meses posteriores buscou maciçamente eleger seus candidatos. Sabemos, entretanto, que o PCB aspirava representar os trabalhadores e que os organismos sindicais são importantes para tal. Dessa forma, não percebemos dicotomia entre os esforços do PCB na disputa eleitoral e na tentativa de organização sindical.

Finalmente, tendo-se conhecimento que Marighella, durante a campanha eleitoral não era um militante com grande inserção entre os comunistas e a

28 Para obter o quociente eleitoral é realizada a divisão da quantidade de votos válidos pela quantidade de cadeiras que o estado tem direito. Os candidatos a deputado na Bahia tiveram 346.493 votos válidos. Dividindo esse total pelas 24 cadeiras que a Bahia tinha direito na Câmara, se obtém o quociente eleitoral que era de 14.437 votos. Logo, a cada 14.437 votos que o partido tinha, se elegia um deputado. 
população baiana, podemos inferir que a sua vitória nas eleições não deve ser atribuída tão somente as suas características pessoais. Entendemos que essa vitória se deveu principalmente pela força que o PCB demonstrou na Bahia, devido a continuidade das suas atividades mesmo nos anos de clandestinidade, além do capital político angariado com vitória da URSS na Segunda Guerra Mundial. Ademais, nesse pleito outros candidatos do PCB eram mais conhecidos do que Marighella, ainda assim ele obteve cerca $30 \%$ dos votos dados aos candidatos a deputado do partido. É plausível pensar então que, em virtude de Marighella fazer parte do Comitê Nacional à época, o partido tenha influenciado seus militantes a votarem prioritariamente nele.

\section{Referências}

A MULHER baiana contra o integralismo. A Tarde, Salvador, 17 jul. 1945.

A MULHER baiana na luta pacífica pela democracia. O Momento. Salvador, 15 out. 1945.

A SEMANA Nacional de Anistia na Bahia. A Tarde. Salvador, 09 abr. 1945. p. 2.

BASBAUM, Leôncio. Uma vida em seis tempos (memórias): uma visão da história política do Brasil dos últimos quarenta anos. São Paulo: Alfa-Omega, 1976.

BRASIL. Lei dos direitos trabalhistas. Disponível em: <http://www.planalto.gov.br/ccivil_03/decreto-lei/ del2848.htm>. Acesso em: 09 set. 2014.

BRASIL. Lei dos Partidos. Disponível em: <http:// www.planalto.gov.br/ccivil_03/leis/19096.htm>. Acesso em: 15 set. 2014 .

CALIL, Gilberto. O integralismo e a defesa de uma "democracia" autoritária e restrita". In: VI SIMPÓSIO NACIONAL ESTADO E PODER: Cultura. Aracaju. 2010. Anais... Aracaju, 2010.

CAVALARI, Rosa Maria Feiteiro. Integralismo: ideologia e organização de um partido de massa no Brasil (1932-1937). Bauru: EdUSC, 1999.

COSTA, Helio. Trabalhadores, sindicatos e suas lutas em São Paulo (1943-1953). In: FORTES, Alexandre et. al. Na luta por direitos: estudos recentes em história social do trabalho. Campinas: Unicamp, 1999. p. 89-121.

FALCÃO, João. O Partido Comunista que eu conheci: 20 anos de clandestinidade. 2. ed. Salvador: Contexto \& Arte, 2000.
FERREIRA, Daniela de Jesus. Tempos de lutas e esperanças: a materialização da revista Seiva (1938-1943). 2012. 189 f. Dissertação (Mestrado) - Programa de Pós-Graduação em História, Universidade Estadual de Feira de Santana, Feira de Santana, 2012.

IBGE. Recenseamento geral do Brasil. Censo Demográfico. 1940. v. 2. Disponível em: <http://biblioteca. ibge.gov.br/visualizacao/periodicos/65/cd_1940_v2_ br.pdf>. Acesso em: 10 set. 2014 .

JOSÉ, Emiliano. Carlos Marighella: o inimigo número um da Ditadura Militar. São Paulo: Sol \& Chuva, 1997.

MAGALHÃES, Mario. Marighella: o guerrilheiro que incendiou o mundo. São Paulo: Companhia das Letras, 2012 .

MARIGHELLA, Carlos. Por que resisti à prisão. 3. ed. São Paulo: Brasiliense; Salvador: EdUFBA; Olodum, 1995.

NOVA, Cristiane; NÓVOA, Jorge (Org). Carlos Marighella: o homem por trás do mito. São Paulo: Unesp, 1999.

O INTEGRALISMO no tribunal da opinião pública. $A$ Tarde, Salvador, 29 maio 1945.

O PARTIDO Comunista e o problema eleitoral. O Momento. Salvador, 06 ago. 1945. p. 6.

O PARTIDO de Representação Popular. A Tarde. Salvador, 19 nov. 1945.

O POVO baiano repele o integralismo: reagirá organizadamente contra as manobras dos fascistas brasileiros. O Momento. Salvador, 28 maio 1945.

PELO voto dos soldados. O Momento. Salvador, 4 maio 1945. p. 2.

PERMITIR a rearticulação integralista é um ultraje à democracia. O Momento. Salvador, 28 maio 1945.

SENA JÚNIOR, Carlos Zacarias Figueirôa de. Os impasses da estratégia: os comunistas e os dilemas da União Nacional na revolução (im)possível - 19361948. 2007. 455 f. Tese (Doutorado) - Programa de Pós-Graduação em História, Universidade Federal do Pernambuco, Recife, 2007.

SILVA, Fernando Teixeira da; SANTANA, Marco Aurélio. O equilibrista e a política: o 'Partido da Classe Operária’ (PCB) na democratização (1945-1964). In: FERREIRA, Jorge; REIS, Daniel Aarão. Nacionalismo e reformismo radical (1945-1964). Rio de Janeiro: Civilização Brasileira, 2007. p. 103-140. 
SILVA, Hélio. 1945: por que depuseram Vargas. Rio de Janeiro: Civilização Brasileira, 1976.

SILVA, Paulo Santos. A volta do jogo democrático: Bahia 1945. Salvador: Assembleia Legislativa, 1992.

SILVA, Paulo Santos. Âncoras de tradição: luta política, intelectuais e construção do discurso histórico na Bahia (1930-1964). Salvador: EdUFBA, 2011.

SILVA, Raquel Oliveira. O PCB e Comitês Populares Democráticos em Salvador: (1945-1947). 2012. $134 \mathrm{f}$. Dissertação (Mestrado) - Programa de Pós-Graduação em História Social, Universidade Federal da Bahia, Salvador, 2012.
SOUZA, Cintia Pinheiro Ribeiro de. A evolução da regulação do financiamento de campanha no Brasil: (1945-2006). 105 f. Dissertação (Mestrado) - Instituto Universitário de Pesquisas do Rio de Janeiro, Rio de Janeiro, 2010.

VAZQUEZ, Petilda Serva. Intervalo democrático e sindicalismo: Bahia (1942-1947). 1986. 238 f. Dissertação (Mestrado) - Universidade Federal da Bahia, Salvador, 1986.

VINHAS, Moises. O Partidão: a luta por um partido de massas: 1922 - 1974. São Paulo: Hucitec, 1982. 